\title{
UMA PROPOSTA PARA O ENSINO DE ORBITAIS ATÔMICOS NO CICLO BÁSICO DOS CURSOS DE ENGENHARIA A PARTIR DA CONSTRUÇÃO DE MODELOS TRIDIMENSIONAIS UTILIZANDO MATERIAIS REUTILIZADOS
}

\author{
MARIN, Letícia ${ }^{1}$; ANACLETO JR., Garbas ${ }^{1}$; BIANCHI, Roberta ${ }^{1}$. \\ ${ }^{1}$ Grupo de Pesquisa em Meio Ambiente e Sustentabilidade (GPMAS) \\ ${ }^{1}$ Universidade São Francisco (USF) - Itatiba, SP \\ Roberta.bianchi@usf.edu.br
}

\begin{abstract}
RESUMO. A química é uma disciplina que apresenta diversas temáticas e dependendo da maneira como é abordada pode tornar seu aprendizado prejudicado. Nesse sentido, ensinar utilizando recursos como, por exemplo, modelos tridimensionais podem facilitar o ensino e a aprendizagem do aluno. As representações tridimensionais normalmente são utilizadas quando são abordados temas como orbitais atômicos, números quânticos, geometria molecular, simetria molecular, entre outros. Nesse sentido, propormos construir kits utilizando materiais que possam ser reutilizados a fim representar estruturas tridimensionais para ensinar orbitais atômicos nas disciplinas de Química dos Cursos de Engenharia.
\end{abstract}

Palavras-chave: Engenharia, ensino de Química, orbitais atômicos, modelos tridimensionais.

ABSTRACT. Chemistry is a subject that presents several themes and depending on how it is approached can impair one's learning. In this sense, teaching using resources such as threedimensional models can facilitate the teaching and learning process. Three-dimensional models are usually used when such topics are covered: atomic orbitals, molecular geometry, molecular symmetry, among others. Here we propose the construction of kits using recycled materials in order to represent three-dimensional structures for the teaching of atomic orbitals in the subject of chemistry in engineering courses.

Keywords: Engineering, chemistry teaching, atomic orbitals, three-dimensional models

\section{INTRODUÇÃO}

A química é conhecida como a ciência que estuda a matéria e as suas transformações, traz consigo infinitas formas para conhecê-la, devido a sua versatilidade de conteúdo. A importância do estudo desta ciência exposta de maniera clara por Cardoso \& Colinvaux (2000, p. 401).

\begin{abstract}
"O estudo da Química deve-se principalmente ao fato de possibilitar ao homem o desenvolvimento de uma visão crítica do mundo que o cerca, podendo analisar, compreender e utilizar este conhecimento no cotidiano, tendo condições de perceber e interferir em situações que contribuem para a deterioração de sua qualidade de vida, como por exemplo, o impacto ambiental provocado pelos rejeitos industriais e domésticos que poluem o ar, água e o solo..."
\end{abstract}

Costumeiramente, em sala de aula, o professor adota metodologias baseadas na transferência de informações para o aluno, geralmente através de aulas expositivas (muitas vezes na forma de leitura de slides) seguidos de exercícios para sua memorização, Este tipo de metodologia de ensino/aprendizagem visa uma supervalorização da formação técnica e dissociação dos 
conhecimentos recebidos passivamente pelo aluno (SOBRAL \& CAMPOS, 2012). Além disso, quando adiciona a seu plano de ensino aulas práticas, estas são utilizadas após a explicação do conteúdo, em uma tentativa de "provar" algum fenômeno estudado em aula.

Assim como as demais disciplinas inseridas nos currículos dos cursos de engenharia, o ensino das ciências, geralmente, se dá pelas leituras de textos didáticos e apresentação dos conteúdos com explicações que privilegiam a memorização. A apresentação da teoria pelo professor para o aluno não permite, muitas vezes a devida contextualização do tema com a área profissional que o aluno optou, tornando a área de estudo cansativa e fazendo com que o discente perca seu interesse nesta, já que, muitas vezes, está relacionado à necessidade de memorizar fórmulas e teorias, o que pode constituir em um obstáculo no seu processo de aprendizagem (KRASILCHIK, 1987).

Já há bastante tempo é possível encontrar na literatura uma série de discussões pedagógicas enfatizando que a obtenção da informação pelo indivíduo de forma passiva (observativa), seguida de memorização e simples reprodução, o coloca meramente como expectador do mundo. Isso impedirá que este indivíduo seja capaz de pensar e agir de modo crítico, o tornando passivo à manipulação de opinião e interesses e dificultando sua vivência em uma sociedade cada vez mais complexa e repleta de tecnologias inovadoras e com tamanha difusão de informações (BARBOSA \& MOURA, 2013).

De acordo com as diretrizes e bases da educação nacional, capítulo IV da educação superior, o Art. 43 em seu inciso I, a educação superior tem por finalidade estimular a criação cultural e o desenvolvimento do espírito científico e do pensamento reflexivo e o inciso III informa que a educação superior deve incentivar o trabalho de pesquisa e investigação científica visando o desenvolvimento da ciência e da tecnologia e da criação e difusão da cultura e, desse modo, desenvolver o entendimento do homem e do meio em que se vive (BRASIL, 1996). Dessa maneira torna-se determinante o uso de novas metodologias de ensino capazes de despertar o senso crítico do discente, agregando à sua formação a capacidade de identificar, agir e refletir perante a uma situação problema, permitindo assim uma autonomia de aprendizagem (FREIRE, 2002).

O docente tem o papel de decidir qual metodologia de ensino é a melhor opção para o tema abordado diante dos alunos que se encontarm em sala de aula. Entretanto, o ato de adotar uma metodologia que permita, de maneira mais efetiva, o incentivo ao aluno para uso de seus sentidos, como visão e tato pode permitir um melhor aproveitamento da aula e garantir um desenvolvimento gradativo de seu senso crítico, permitindo que esse aluno consiga fazer parte do processo de construção de conhecimento e assim, da teorização que é necessária para o tema abordado (BERBEL, 2011).

Pensando numa nova abordagem de ensino, Marin e Colaboradores (2010), vêm trabalhando com metodologias ativas na Faculdade de Medicina de Marília onde a aprendizagem é baseada em problemas (ABP). A aprendizagem baseada em problemas (ABP) é um método de ensino em que os alunos trabalham intencionalmente com problemas reais ou simulados, por um período de tempo, desenvolvendo habilidades, como por exemplo, senso crítico, trabalho em grupo, diferentes modos de resolução de problemas, entre outros (CYRINO e TORALLES-PEREIRA, 2004).

Teixeira e colaboradores (2006) utilizaram a metodologia aprendizagem baseada em projetos (Design based learning) para otimizar o processo de aprendizagem do tema Geometria Descritiva. A aprendizagem baseada em projetos é um modelo que organiza o processo de aprendizagem em torno de projetos, os quais podem ser definidos como tarefas complexas baseadas em desafios ou problemas que envolvem os alunos no design, na solução de problemas, na tomada de decisões e em atividades investigativas e de pesquisa (Thomas, 2000). 
Para tornar as aulas de Química mais prazerosa e interessante, algumas maneiras podem ser adotadas para facilitar esse processo, como, por exemplo, utilizar ferramentas como a criação de kits que representam modelos tridimensionais para auxiliar no ensino de orbitais atômicos.

Orbitais atômicos é a denominação dos estados estacionários da função de onda de um elétron (funções próprias do Hamiltoniano $(H)$ na equação de Schrödinger $(H \psi)$ onde $\psi$ é a função de onda). Entretanto, os orbitais não representam a posição exata do elétron no espaço, que não pode ser determinada devido à sua natureza ondulatória, apenas delimitam uma região do espaço na qual a probabilidade de encontrar o elétron é mais alta (ORCHIN, et al., 2005).

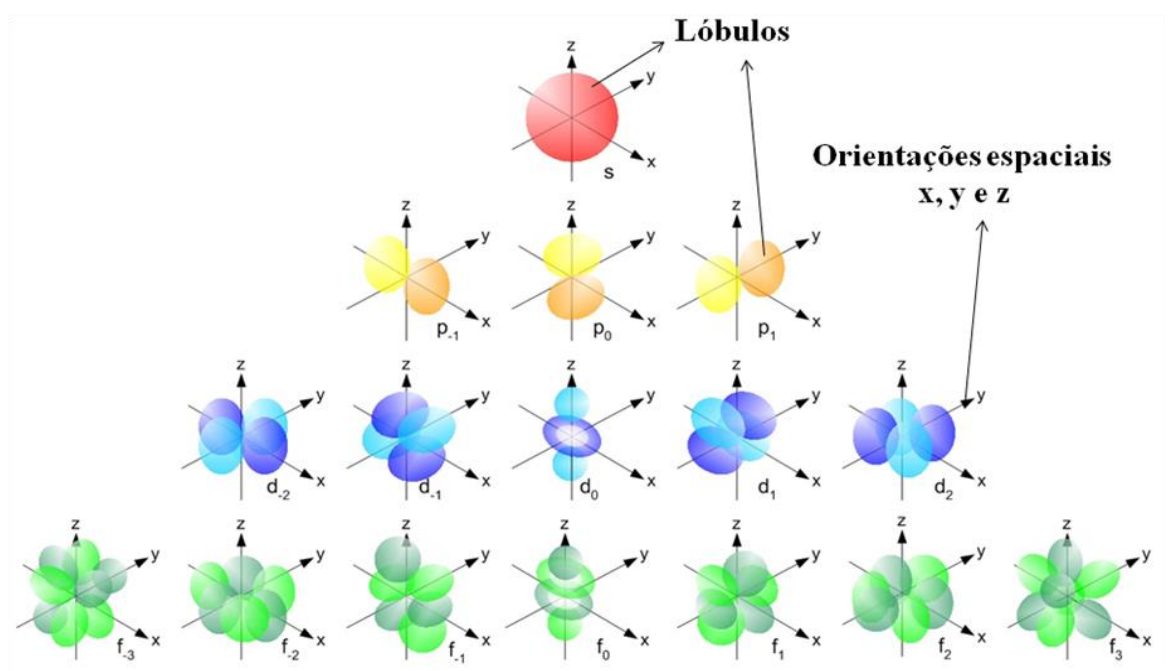

Figura 1. Modelos de orbitais atômicos s, p, d e f. (Fonte: UCDavis Chemwiki, CC BY-NCSA 3.0 US. Disponível em:< https://pt.khanacademy.org.> Consultado em 27 de Nov. 2017).

A partir da temática abordada acima, o objetivo desse trabalho é montar kits de aula que representem modelos tridimensionais, a fim de auxiliar no ensino/aprendizagem dos conteúdos da disciplina de Química dos cursos de Engenharia.

\section{METODOLOGIA}

Os kits dos modelos tridimensionais foram confeccionados por uma aluna de Iniciação Científica da USF a partir da reutilização de materiais como: plásticos, madeira, vidro e materiais metálicos. Os kits foram construídos de maneira a permitir a interação do aluno na hora da montagem do modelo tridimensional proposto na atividade em sala de aula. Como, por exemplo, durante a problemática sobre a região de probabilidade de não encontrar o elétron, o aluno fica a vontade para manipular seu modelo de acordo com a sua percepção.

\section{Materiais}

- Régua

- Caneta

- Tesoura

- Pincel

- Bexiga

- Barbante
- Jornal

- Tinta Guache

- Cola especial: cola + água + amido de milho

- Espuma de colchão descartado para reciclagem

- Pedaços de roupas rasgadas

- Madeira (utilizada em construção de casas) 
- Canudo

- Agulha

\section{Procedimento}

\section{Confecção dos lóbulos do Modelo Orbital Atômico}

Foram estudadas diversas maneiras de confeccionar os lóbulos dos modelos dos orbitais atômicos.

- Lóbulo do Orbital feito de Fuxico: utilizou-se pedaço de roupas, e com a agulha e linha alinhavou o pano, dentro colocou uma espuma de colchão para dar um formato redondo e oval, representando os lóbulos dos orbitais s e p, respectivamente.

- Lóbulo do Orbital feito de Jornal: utilizaram-se bexigas como molde para fazer o formato dos lóbulos dos orbitais, em seguida picotou as folhas de jornal, e colou-as nas bexigas com a cola especial. Após secar foram pintadas primeiramente de guache branco e depois com o guache colorido.

- Lóbulo do Orbital feito de barbante: utilizaram-se bexigas como molde, em seguida mergulhou o barbante em um pote que continha cola especial com um pouco de guache e em sequência enrolou-os nas bexigas e esperou secar.

Confecção das estruturas (Orientações Espaciais x, y e z):

- Com jornais: Os jornais foram medidos para que tivessem cerca de $28 \mathrm{~cm}$ de comprimento, em seguida cortados e feito rolinhos, após isso foram pintados com tinta guache preta. Para o pedestal foi utilizado retalhos de madeira de demolição e foi realizado um furo central para ser fixada a estrutura.

- Com canudinhos recicláveis. Após a coleta deles, foram lavados e limpos para os alunos utilizarem.

\section{RESULTADOS E DISCUSSÃO}

\section{Montagem}

A confecção dos lóbulos dos orbitais atômicos tornou-se eficiente apenas com o jornal e o barbante. Os lóbulos feitos de Fuxico tornaram-se inviáveis, devido o tempo empregado nelas e principalmente porque seu formato não ficou conforme o desejado, outro fator foi o seu tamanho, ficaram pequenas em relação a estrutura, conforme apresentado na Figura 2.

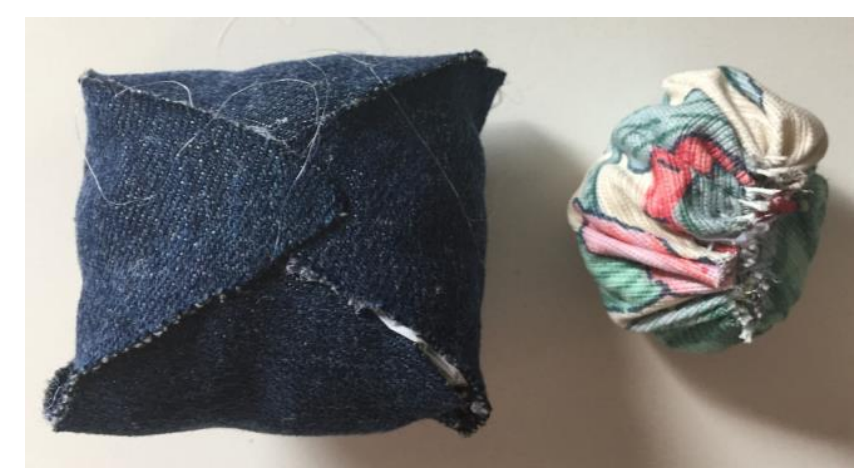

Figura 2. Modelos dos lóbulos dos Orbitais feitos a partir de fuxico.

Os lóbulos dos orbitais fabricados a partir do jornal tornaram-se eficientes, pois o seu formato ficou conforme o desejado, o único fator negativo é que o jornal demora cerca de 10 a 15 dias para sua secagem total. Para viabilizar esse problema, utilizaram-se meios para 
acelerar o processo de secagem, como por exemplo, o uso do secador. Contudo, não foi eficiente como o esperado, pois ele secou apenas a parte externa. A Figura 3 ilustra a confecção dos orbitais de jornal.

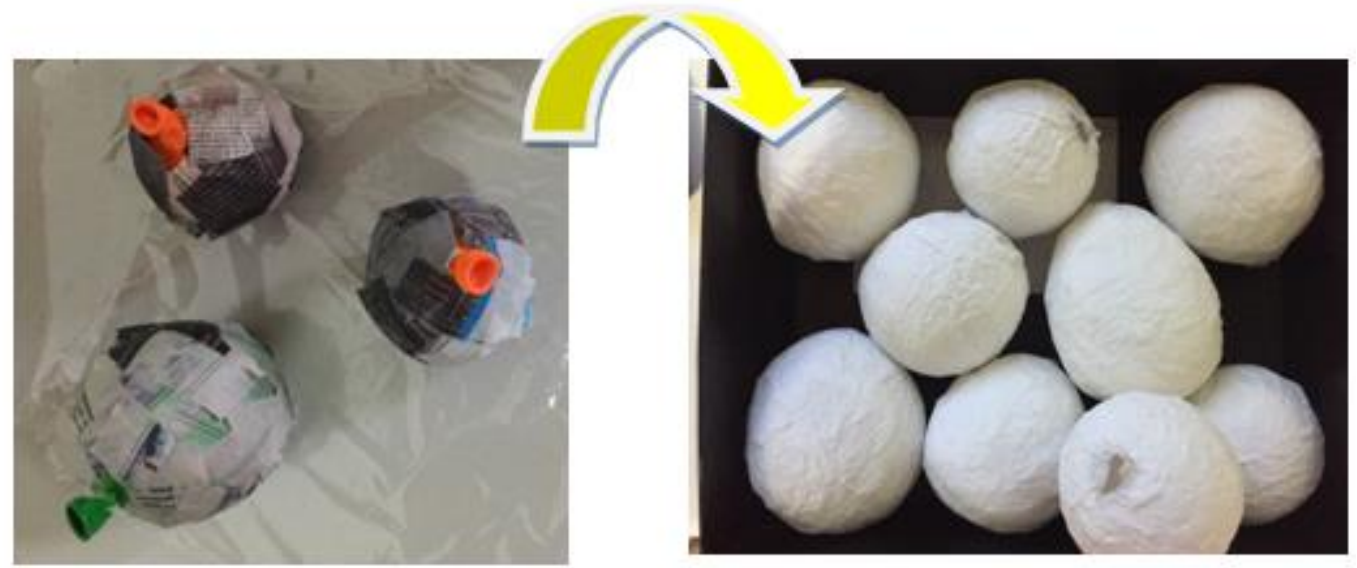

Figura 3. Passo a Passo dos Lóbulos dos Orbitais confeccionados com Jornal.

Os Lóbulos dos orbitais fabricados de barbantes foram as mais eficientes entre as três, pois com o secador elas secaram completamente e suas estruturas ficaram fixas, conforme apresentada na Figura 4.

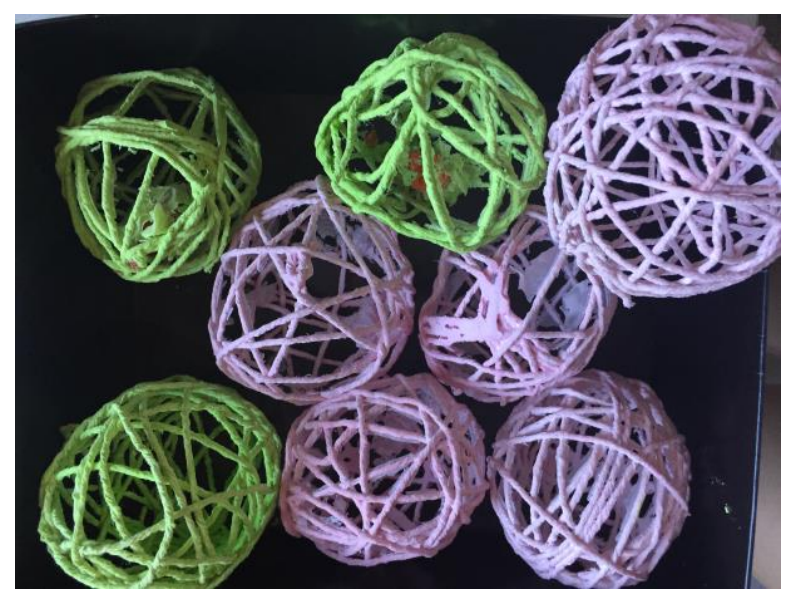

Figura 4. Modelos dos Orbitais confeccionados de barbante.

As estruturas (que demonstram a orientação espacial) construídas tanto com o jornal como com o canudo (Figura 5 (A) e (B), respectivamente, trouxeram resultados positivos, pois, suportaram os pesos dos lóbulos dos orbitais.
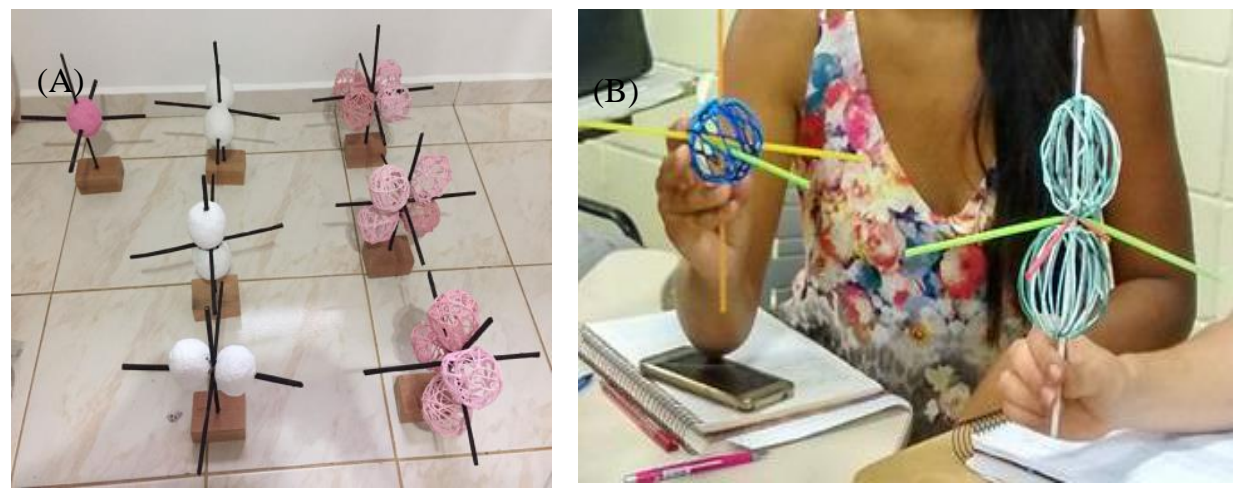

Figura 5. Estruturas (A) de Jornal e (B) de canudo. 
Depois de prontos os kits foram acondicionados em uma caixa totalmente desmontados (estruturas separadas dos lóbulos).

\section{Aplicação em Sala de Aula}

A utilização dos kits em sala de aula ocorreu na disciplina de Química e Ciências dos Materiais dos cursos de Engenharia Química e Engenharia Mecânica da Universidade São Francisco - Campus Itatiba sob a supervisão da Profa. Dra. Roberta Bianchi, quando foi abordado o tema sobre Teoria atômica e estrutura eletrônica dos átomos.

Inicialmente os alunos foram divididos em grupos e cada um recebeu os materiais dos kits (estruturas e lóbulos). Foi solicitado que cada grupo representasse os modelos dos orbitais atômicos s, p, d e f, indicando quantos elétrons cada orbital acomodam e a região de probabilidade zero de não encontrar o elétron. Após a montagem do modelo orbital tridimensional, cada grupo fez a sua explanação, como mostra a Figura 6.

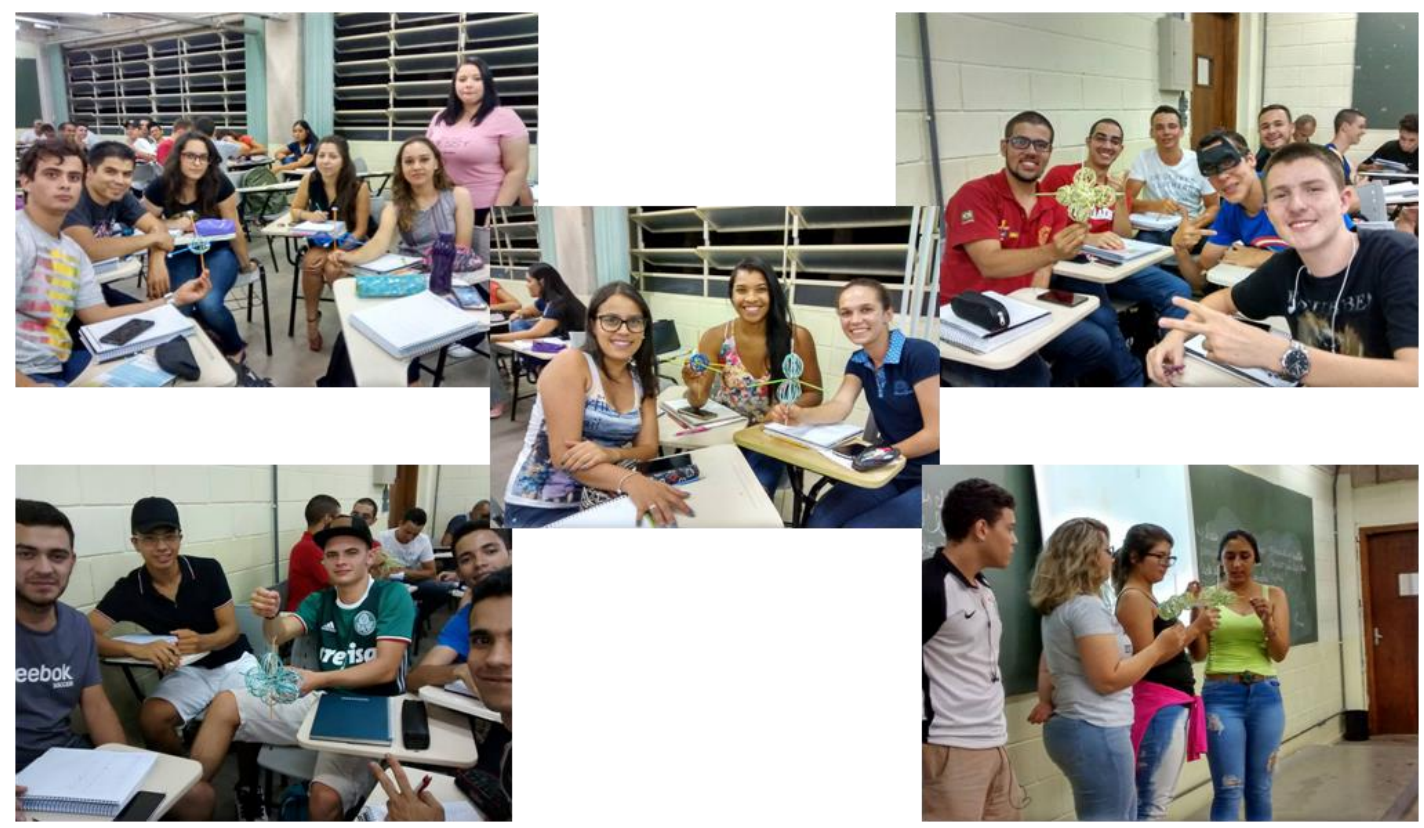

Figura 6. Modelos de Orbitais Atômicos tridimensionais, montado pelos alunos, a partir do Kit confeccionado.

A proposta de ensino adotada nessa aula pode ser chamada de sala de aula invertida, coloca o aluno no centro do processo ensino aprendizagem, como protagonista e, promove o desenvolvimento de uma aprendizagem ativa, investigativa e colaborativa (BERGMANN, 2016). Além disso, estimula o trabalho em grupo, fato esse muito importante já que, muitas pessoas ficam cada vez mais enclausuradas em seus dispositivos eletrônicos.

O que foi notado pela professora durante a apresentação de alguns grupos certa confusão na hora de expressarem a região de probabilidade zero de não encontrar o elétron e quantos elétrons cada orbital atômico poderia acomodar. Com relação a localização dos elétrons, muitos grupos disseram que a região de probabilidade de não encontrar os elétrons era nos lóbulos dos orbitais. No entanto, a região certa se chama Plano Nodal, e localiza-se entre os lóbulos, como mostra a Figura 7. Ao apontarem quantos elétrons cada orbital poderia acomodar muitos grupos se confundiram, por exemplo, alguns disseram que o orbital s pode acomodar no máximo 1 elétron e o orbital p pode acomodar até 2 elétrons. Após a explanação de todos os grupos, a professora explicou que o orbital s é um orbital esférico, menos energético e que pode acomodar no máximo dois elétrons. Já o orbital p é um orbital em que os lóbulos estão representados nos três planos cartesianos, px, py e pz (Figura 7) e cada um 
acomoda no máximo dois elétrons, dessa maneira o orbital atômico p pode acomodar no máximo 6 elétrons. A distribuição de quem recebe o elétron primeiro é de acordo com o nível de energia, sendo o menos energético primeiro.

As respostas apresentadas por alguns grupos que se confundiram é extremamente aceitável já que o tema abordado é complexo. Além disso, nem todos têm a facilidade em visualizar os modelos em três dimensões. Nos moldes tradicionais de ensino, são trabalhados modelos 1D ou 2D para ensinar a Teoria atômica e estrutura eletrônica.

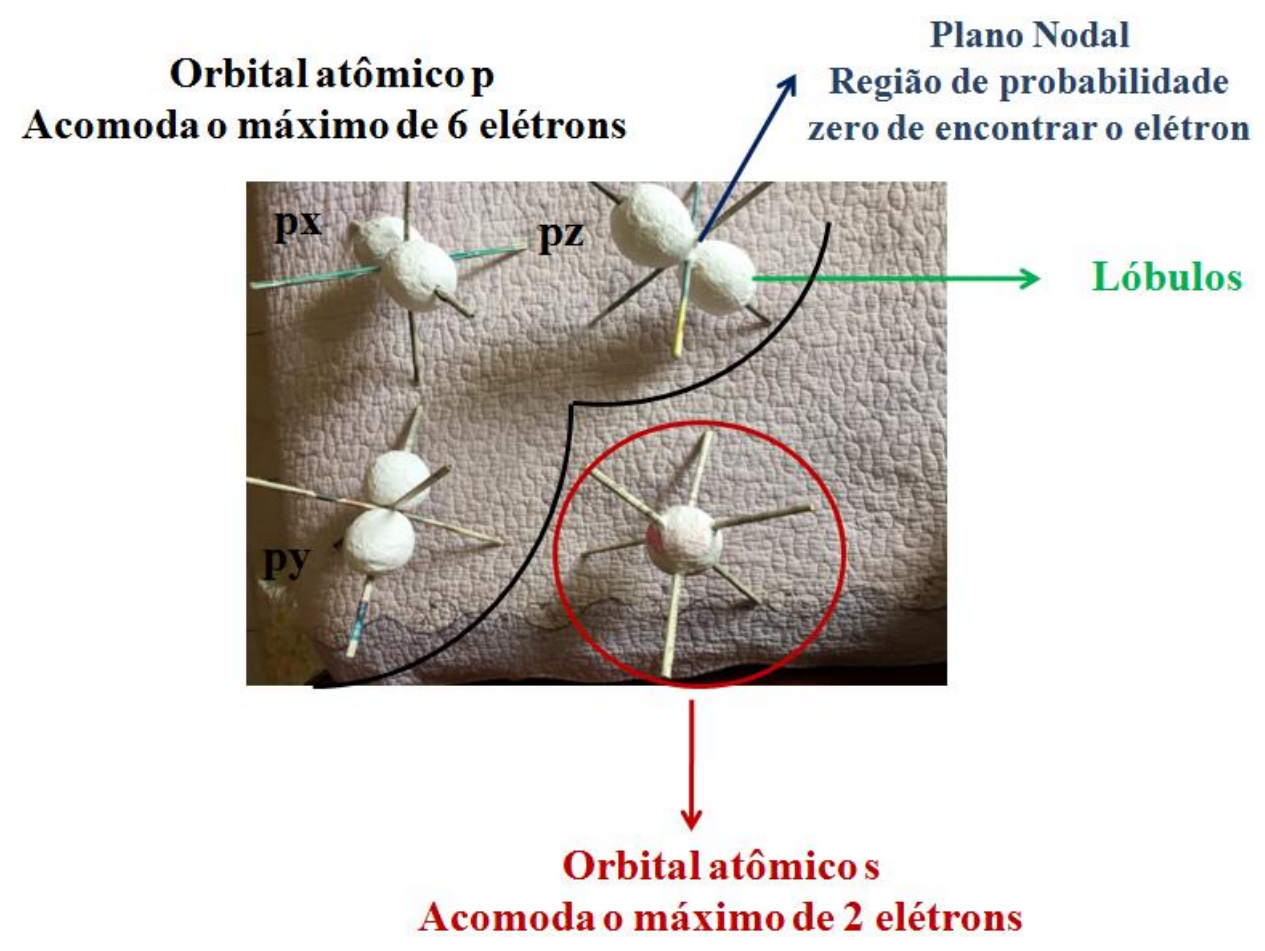

Figura 7. Representação do orbital atômico s e p e o Plano Nodal.

\section{CONCLUSÃO}

As dificuldades enfrentadas pelos alunos nas visualizações e entendimento das estruturas tridimensionais, apresentados em salas de aula por meio das lousas, papeis ou em slides vêm despertando interesse entre docentes e pesquisadores para que haja uma alternativa no sentido de despertar mais empenho e maior interação do aluno no processo de ensino/aprendizagem. Nesse sentido, as metodologias ativas baseadas em problemas, projetos ou a sala de aula invertida, vem sendo muito utilizada, permitindo ao aluno a participação de forma ativa na construção do seu conhecimento.

A construção de kits para montagem de modelos orbitais atômicos tridimensionais se mostrou eficaz no ensino de Teoria atômica e distribuição eletrônica. Os alunos puderam montar seus próprios modelos e investigar a região de probabilidade zero de encontrar os elétrons. Além de contabilizar quantos elétrons cada orbital atômico podia acomodar. Embora seja uma maneira lúdica de ensinar, os alunos puderam trabalhar algumas habilidades como o trabalho em grupo, promovendo as relações interpessoais entre os alunos, estimular a criatividade e a busca por novos conhecimentos.

\section{AGRADECIMENTOS}

Agradecemos o Programa de Iniciação Científica, de Iniciação Tecnológica e de Extensão - PICITExt pela bolsa de Iniciação Científica concedida. 


\section{REFERÊNCIAS}

ATKINS, P. \& JONES L., Princípios de Química Questionando a Vida Moderna e o Meio Ambiente, $5^{\text {a }}$ ed., 2013.

BARbOSA, E. F.; MOURA, D. G. B. Tec. SENAC, v. 39, n.2, Rio de Janeiro, p.48-67, mai/ago. 2013.

BERBEL, N. A. N.; Semina: Ciências Sociais e Humanas, Londrina, v. 32, n. 1, p. 25-40, jan./jun. 2011.

BELTRAN, N.O Química Nova na Escola: Idéias em Movimento, n. 5, 1997.

BERGMANN, J., Sala de aula invertida. Grupo Gen - LTC: 2016.

BRASIL. Presidência da República. Casa Civil. Subchefia para Assuntos Jurídicos. Lei ${ }^{\circ}$ 9.394, de 20 de dezembro de 1996. Estabelece as diretrizes e bases da educação nacional. Disponível em: <http://www.planalto.gov.br/ccivil_03/Leis/L9394.htm> Acesso em 27 Nov. 2017.

CARDOSO, S. P.; COLINVAUX, D. Explorando a Motivação para Estudar Química. Quím. Nova, v. 23, n. 3, p. 401-404, maio/jun. 2000.

CYRINO, E. G., TORALLES-PEREIRA, M. L., Trabalhando com estratégias de ensinoaprendizado por descoberta na área da saúde: a problematização e a aprendizagem baseada em problemas. Cad. Saúde Pública, Rio de Janeiro, 20(3):780-788, mai-jun, 2004.

DUARTE H. A., Ligações Química: Ligação Iônica, Ligação Covalente, Ligação Metálica, Cadernos Temáticos de Química Nova na Escola, n.4, 2001.

FREIRE, P. Pedagogia da autonomia. Saberes Necessários à prática educativa. $25^{\mathrm{a}}$ Ed. São Paulo, Paz e Terra, 2002.

HOUSECROFT, C.E. \& SHARPE, A.G., Química Inorgânica, vol. 1, 4ª ed, 2013.

KRASILCHIK, M. O Professor e o Currículo das Ciências. São Paulo: EPU, 1987.

MARIN, M. J. S., LIMA, E. F. G., PAVIOTTI, A. B., MATSUYAMA, D. T., SILVA, L. K. D. d., GONZALEZ, C., DRUZIAN, S. and ILIAS, M., Aspectos das fortalezas e fragilidades no uso das metodologias ativas de aprendizagem. Revista Brasileira de Educação Médica 2010, 34, 13-20.

ORCHIN, M., MACOMBER, R. S., PINHAS, A., WILSON, R. M. Atomic Orbital Theory, 2005 Disponível em: http://media.wiley.com Acesso em 27/Nov. 2017.

SCHNETZLER, R.P. Química Nova na Escola: A Pesquisa no Ensino de Química e a Importância da Química Nova na Escola, n. 20, 2004.

SOBRAL, F. R.; CAMPOS, C. J. Ver. Esc. Enfermagem USP, 46, p. 208-18, 2012.

TEIXEIRA, F. G., SILVA, R. P., SILVA, T. L. K., HOFFMANN, A. T. Geometria 
Descritiva: Aprendizagem baseada em Projetos. COBENGE - Ensino de Engenharia: Empreender e preservar, (54) 3316-8219, 2006.

TOSTES, J. G., Química Nova na Escola: Estrutura Molecular, n. 7, 1998.

THOMAS, J.W. A review of research on project-based learning. Relatório técnico. Autodesk Foundation, 2000. Disponível em: < http://www.autodesk.com/foundation> Acesso em 27 de Nov. de 2017:

VERA, L. \& QUEIROZ, S.L. Química Nova na Escola: Contribuições para o Desenvolvimento de Atividades Didáticas, Vol. 37, n. 2, p. 133-139, São Paulo, 2015. 